Trauma Surgery \& Acute Care Open

\title{
American Association for the Surgery of Trauma Prevention Committee review: Family Justice Centers - a not-so-novel, but unknown gem
}

\author{
Thomas K Duncan (10 , ${ }^{1}$ Ronald Stewart, ${ }^{2}$ Kimberly Joseph, ${ }^{3,4}$ Deborah A Kuhls, ${ }^{5}$ \\ Tracey Dechert, ${ }^{6}$ Sharven Taghavi, ${ }^{7}$ Stephanie Bonne, ${ }^{8}$ Kazuhide Matsushima ${ }^{9}$
}

'Department of Surgery, Ventura County Medical Center, Ventura, California, USA

2Department of Surgery, The University of Texas Health Science Center at San Antonio, San Antonio, Texas, USA ${ }^{3}$ Department of Trauma, John H Stroger Hospital of Cook County, Chicago, Illinois, USA ${ }^{4}$ Chair, ATLS Subcommittee Committee of Trauma of the American College of Surgeons, American College of Surgeons, Chicago, Illinois, USA ${ }^{5}$ Department of Surgery, University of Nevada Las Vegas School of Medicine, Las Vegas, Nevada, USA

${ }^{6}$ Department of Surgery, Boston Medical Center, Boston, Massachusetts, USA ${ }^{7}$ Division of Trauma and Critical Care, Tulane University School of Medicine, New Orleans, Louisiana, USA

${ }^{8}$ Department of Surgery, Rutgers University, Newark, New Jersey, USA

${ }^{9}$ Department of Surgery, Los Angeles County University of Southern California Medical Center, Los Angeles, California, USA

\section{Correspondence to} Dr Thomas K Duncan; thomas. duncan@ventura.org

Received 26 February 2021 Accepted 13 May 2021

\section{(c) Author(s) (or their} employer(s)) 2021. Re-use permitted under CC BY-NC. No commercial re-use. See rights and permissions. Published by BMJ.

\begin{tabular}{l}
\hline To cite: Duncan TK, \\
Stewart R, Joseph K, et al. \\
Trauma Surg Acute Care Open \\
2021;6:e000725.
\end{tabular}

\section{ABSTRACT}

The American College of Surgeons Committee on Trauma requires that trauma centers demonstrate adequate financial support for an injury prevention program as part of the verification process. With the ongoing challenges that arise with important social determinants of health, trauma centers have the important task of navigating a patient through the complex process of obtaining services and tools for success. This summary from the American Association for the Surgery of Trauma Prevention Committee focuses on a model that has been present for several years, but has not been brought to full awareness in the trauma world. It highlights the importance of the Family Justice Center concept that brings a multitude of organizations under one roof, thus eliminating the hurdles encompassed by trauma patients, seeking life-changing resources necessary to mitigate the impact of both community violence exposure and intimate partner/domestic violence. It discusses the potential benefits of a partnership between trauma centers and Family Justice Centers and similar models. Finally, it also raises awareness of important programmatic evaluation research required in the arena of injury prevention targeting a population whose outcomes are difficult to measure.

\section{INTRODUCTION}

Domestic violence (DV) is a public health issue which crosses families, communities, and populations. ${ }^{1-4}$ Some risk factors and social determinants of health that have an impact on the prevalence of violence are: hopelessness, unemployment (although it affects all social classes), access to firearms, lack of housing, lack of role models, mental illness, and substance abuse. ${ }^{12}$ DV includes violence against partners, children, parents, or the elderly, whereas intimate partner violence (IPV) involves violence that occurs in a close relationship and is not specific to only those associations with sexual intimacy. The Centers for Disease Control and Prevention (CDC) defines DV or IPV as 'physical violence, sexual violence, stalking, or psychological harm by a current or former partner or spouse'. ${ }^{56}$ On average, 50 women in the USA are killed with a firearm by intimate partners each month. Abused women are five times more likely to be killed if the person abusing the woman owns a firearm. ${ }^{178}$ The American College of Obstetrics and Gynecologists issued a statement noting that women disproportionately experience IPV, and abusers with access to a firearm within those relationships are a key risk factor for intimate partner homicide. ${ }^{129}$

According to the CDC, one in four women and one in seven men in the USA have experienced violence (sexual, physical) and/or stalking from an intimate partner in their lifetime; and the risks to victims are potentially severe. CDC data link IPV with an increased risk of injury and death. ${ }^{171011}$ Although both men and women are harmed by IPV, women more frequently experience severe consequences of IPV and suffer life-threatening injuries. ${ }^{12}{ }^{13}$ The disproportionate impact of IPV on women is apparent in homicide data which demonstrate that $42 \%$ of female murder victims are killed by an intimate partner, as compared with 5\% of men who sustain fatal injuries with an intimate partner as the perpetrator. ${ }^{12} 1415$ Almost half of women murdered by an intimate partner have a documented emergency department (ED) visit within 2 years prior to their death. ${ }^{12} 15$ These patients often present with traumatic injuries, which provide surgeons, emergency physicians and nurses an opportunity to break the cycle of violence. ${ }^{12}$

In the USA, about 20 people per minute are physically abused by an intimate partner, which equates to 10 million people abused annually from intimate partners. ${ }^{16} 17$ Twenty-two percent of women and $14 \%$ of men are harmed by at least one act of severe physical violence by an intimate partner at some point in their lifetime. These data translate to an incidence of nearly 2.8 million women and more than 2.3 million men severely injured annually. ${ }^{1717}$ This toll of abuse is significantly more common than other diseases, such as breast cancer and heart disease. ${ }^{18}$ Almost 23 million women and 1.7 million men have been the victim of completed or attempted rape at some point in their life.

There appear to be disparities regarding the impact of DV/IPV in certain ethnic populations, and among the lesbian, gay, bisexual, transgender, queer community. ${ }^{78}$ A recent survey indicates that higher rates for Native American women persist, but disproportionately high rates are now also observed in multiracial $(56.6 \%)$ and non-Hispanic black (45.1\%) women. ${ }^{719}$ Women with disabilities are more vulnerable to rape and sexual coercion, along with several forms of IPV. ${ }^{10}$

IPV is under-reported and often goes unrecognized by family members, friends, and healthcare providers. This may be due to a propensity of patients who experience IPV not to disclose the 


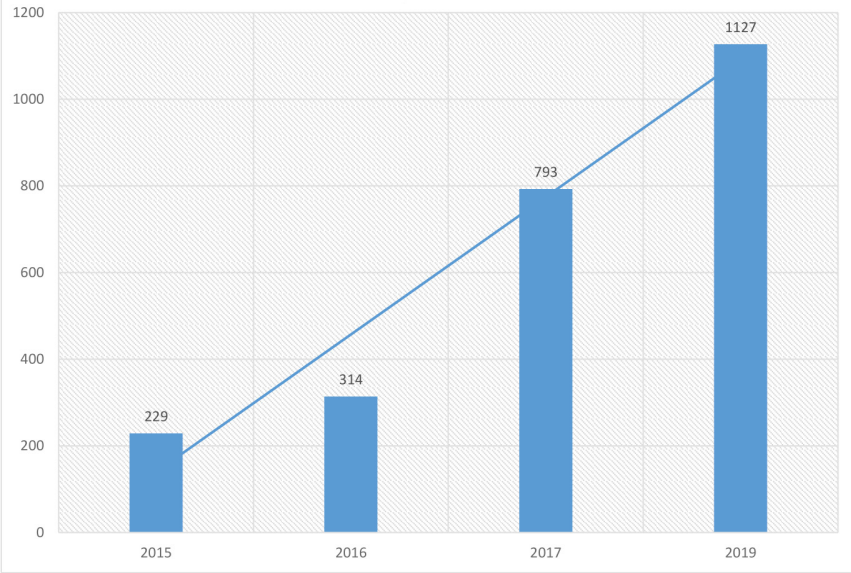

Figure 1 Camp HOPE participants: by year.

violence unless prompted by family, friends or healthcare professionals. Available data demonstrate that only about one in four women patients will offer spontaneous testimony of an IPV incident. ${ }^{12} 20$

No one is immune from IPV; not even surgeons or other physicians. Although the true prevalence of IPV among US surgeons is unknown, it is important to note that anyone can be a victim regardless of income, education, race, ethnicity, age, or professional role. ${ }^{16}$ Collectively, the authors of this article have eight physician colleagues who were killed by IPV.

Community violence exposure in the form of a child being subjected to either DV or IPV involving a parent deserves mention because it has direct bearing on the physical, mental, and emotional development of children. Increased stress levels among parents are often a significant predictor of physical abuse and neglect of children, in addition to neighborhood poverty. ${ }^{110}$ If the parent is unable to access professional support after DV or IPV, the exposed child will also not receive assistance or treatment. This may contribute to lifelong mental health and physical health problems for the child such as chronic disease, anxiety, substance abuse, depression and physical violence. ${ }^{1}{ }^{19} 21$ The Family Justice Center (FJC) concept provides services to address root causes of these issues to mitigate preventable lasting effects.

Researchers estimate that upwards of 18.8 million children in the USA witness DV across their lifetime. ${ }^{22}{ }^{23}$ Meta-analytic studies consistently find that children exposed to DV are at a higher risk for emotional, social, and behavioral difficulties both in the short term and long term. ${ }^{2224-26}$ Moreover, children exposed to DV experience additional stresses associated with the trauma of repeated separations, child custody battles, and isolation from extended family supports. Children exposed to DV are also at a significantly higher risk for abuse and neglect. ${ }^{27}$ ${ }^{28}$ While the research on exposure to DV continues to emerge, existing evidence suggests these children are at risk for propensity to perpetuate the cycle of DV. ${ }^{27-31}$ The higher the exposure to childhood trauma, the higher the rates of impaired social, emotional and cognitive functions, health/behavioral risk factors, acute and chronic diseases, disability, early death and risk for intergenerational transmission of adverse childhood experiences. ${ }^{27} 3233$ Given the prevalence of children exposed to DV in the USA and the negative consequences on their future, an effective system-level intervention is needed to provide children the opportunity to develop positive childhood events and positive coping mechanisms that allow for resiliency and ability to thrive in difficult environments. ${ }^{27}$

\section{THE FJC MODEL}

\section{Development}

The FJC concept began in San Diego, California by Casey Gwinn, JD (president) and Gael Strack, JD (CEO) in 1989, and led to the creation of Alliance for HOPE International in 2002, of which Chan Hellman, PhD of the University of Oklahoma, Tulsa is the lead researcher. ${ }^{34}$ As of 2021, there are FJCs in 43 states in the USA and 25 countries around the world. ${ }^{34} 35$ There are now over 130 FJCs in the USA, approximately 17 in California, ${ }^{36}$ and currently a state-wide movement in Georgia. ${ }^{34}$ Of these centers, 37 are formally affiliated with the FJC Alliance, as of January 31, 2021. FJCs are codified in the federal Violence Against Women Act. CA SB 557 (Senator Kehoe); AB 1623 (Majority Leader Atkins).$^{37}$ It was the first state legislation in the USA focused on defining and evaluating FJCs. FJCs are defined as:

Multiagency, multidisciplinary service centers where public and private agencies assign staff members on a full time or part-time basis in order to provide services to victims of DV, sexual assault, elder abuse or human trafficking from one location in order to reduce the number of times victims must tell their story, reduce the number of places victims must go for help and increase access to services and support for victims and their children. ${ }^{38}$

In 2003, US President George W Bush put forth the President's FJC Initiative to provide \$20 million to 15 communities to help them establish pilot FJCs in communities across the country. This initiative used the San Diego FJC as its model. ${ }^{35} 3940$ The US Department of Justice views the FJC model to be a best practice approach in responding to DV. ${ }^{39}$ They recognize disparities in care regarding people of color, and endeavor to encourage importance of promoting human rights. ${ }^{6}$

\section{Program details}

Programs provided by Alliance for HOPE International include, but are not limited to ${ }^{6}$ :

- FJC Alliance: assists in supporting interested communities with the necessary tools required to establish and sustain a functional Family Justice multiorganizational center.

- Training Institute on Strangulation Prevention: teaches management of non-fatal strangulations to increase the knowledge base of professionals (medical providers, law enforcement agents, etc) involved in the management of DV and sexual assault victims who are strangled. The institute also amplifies advocacy among the legal and medical communities.

- Camp HOPE America: evidence-based mentoring and camping summer program that provides an intervention for children exposed to DV by developing resilience, hope, and character.

- VOICES Survivor Network: volunteer network of DV and IPV survivors working in a collaborative multidisciplinary fashion to break generational cycles of violence and abuse in families, leading to economic justice and healing.

- Justice Legal Network: assists victims with civil legal advocacy, including but not limited to: matrimonial law, immigration law, disability representation, and elder protection. ${ }^{34}$ Acquiring up-to-date knowledge to appropriately care for strangulation victims, and skills necessary for financial liberation and parenting are critical. Victims of IPV may suffer near and nonfatal strangulation that may go unrecognized due to lack of identification of clinical signs. Alliance for HOPE's Training Institute 
Table 1 Children's Hope Index (CHI) scores before and after Camp HOPE

\begin{tabular}{lllll}
\hline & $\mathbf{2 0 1 5}(\mathbf{n}=\mathbf{2 2 9})$ & $\mathbf{2 0 1 6}(\mathbf{n}=\mathbf{3 1 4})$ & $\mathbf{2 0 1 7}(\mathbf{n}=\mathbf{7 9 3})$ & $\mathbf{2 0 1 9}(\mathbf{1 1 2 7})$ \\
\hline Pretest CHI score (mean) & 25.38 & 25.15 & 25.72 & 25.92 \\
Post-test CHI score (mean) & 27.51 & 25.93 & 26.19 & 26.56 \\
Follow-up CHI score (mean) & 28.67 & 26.75 & 27.06 & 27.43 \\
\hline
\end{tabular}

on Strangulation Prevention focuses on addressing near and non-fatal strangulation cases in DV, sexual assault, elder abuse, and child abuse cases. ${ }^{41}$ The institute trains medical personnel, staff caring for DV/IPV victims, as well as victims/family/friends. The FJC offers four 6-week financial literacy courses to clients each year. A 10-week dual track parent/child program called 'Stepping Stones' is offered three times per year. ${ }^{42}$

The VOICES Survivor Network is an important aspect of the FJC, where survivors encourage each other, and support and shepherd one another along the way to liberation.

The International Family Justice Center Conference is the only national and international violence prevention conference focused on the development of multiagency, multidisciplinary teams in every community in America and around the world. ${ }^{6}$

The resources and structures of these Centers vary across communities. However, best practice approaches recommended for developing FJCs include: colocated multidisciplinary services for victims and children; law enforcement agencies with proactive arrest or mandatory arrest policies for offenders; enforceable prohibitions against offenders on the site of the Center; trained professionals who already work with DV issues within the community; elected officials and other community policymakers who support the Center; a thorough planning process that guides the development of the Center; and widespread support from community members. ${ }^{39} 42$

\section{Benefits to individuals/community}

The ultimate goals of FJCs are to promote victim safety and hold offenders accountable ${ }^{42} 43$ by coordinating, monitoring and risk assessment and management, though law enforcement is not the central focus of intervention and prevention efforts. ${ }^{38} 42-44$

This coordination reduces the risk of 'intimate terrorism'defined as physical abuse plus a broad range of tactics designed to maintain control over the other person in the relationship, that is more likely to be serious and to escalate over time. ${ }^{45}$ Multiple studies have noted that when compared with all other groups, African-American women are more likely to experience 'dual arrest' (eg, be arrested along with the perpetrator), as well as prosecution in cases involving IPV; but the FJC model of working with law enforcement and multiple other agencies seeks to eliminate such occurrences by incorporating teachings on how to eradicate systemic racism. ${ }^{76-48}$

In a multi-institutional pilot study involving just under 4500 survivors, the two most common reasons for seeking services across the four pilot sites were abuse-related assistance (talking

\begin{tabular}{ll}
\hline $\begin{array}{l}\text { Table } 2 \\
\text { and after Camp HOPE }\end{array}$ & $\begin{array}{l}\text { Analysis of variance for Children's Hope Index scores before } \\
\text { Year }\end{array}$ \\
\hline 2015 & ANOVA \\
\hline 2016 & $(F(2,172)=9.22 ; p<0.05)$ \\
2017 & $(F(2,115)=6.33 ; p<0.05)$ \\
2019 & $(F(2,393)=12.13 ; p<0.05)$ \\
\hline
\end{tabular}

ANOVA, analysis of variance. to someone about DV/counseling) and legal aid (filing restraining orders, and help with immigration issues). Case management and shelter/housing were the third and fourth highest, including child support/visitation assistance. Greater than 50\% of survivors received services in the same day, and nearly $50 \%$ of survivors returned for services after their initial contact with FJCs. ${ }^{49}$

By incorporating the important social determinants of health model, the objective is to provide evidence-based services for DV, IPV, elder abuse, sex traffic, and child abuse victims. The aim is not replacing or duplicating programs, but taking existing resources and putting them under the same roof by providing more opportunities to coordinated services. Increased access to services should lead to streamlined case management and improved interagency communication. This model is identical to the comprehensive cancer center concept promoted by the American College of Surgeons Commission on Cancer where a multidisciplinary team provides cancer services to an unfortunate patient afflicted with cancer within the same building. This allows for integrated coordinated collaborative comprehensive cancer care. ${ }^{50}$ It also mirrors the pediatric and women's health concept of providing a myriad of services under one umbrella, and the Trauma Recovery Center (TRC) model.

TRCs function similarly to FJCs by providing comprehensive psychological, forensic testing, and survivor network services, in addition to helping clients navigate the criminal justice system. These services are provided to victims of any violent crime, DV, sexual assault (and other physical assaults), criminal motor vehicle crashes, gang-related violence, and loss of a loved one to homicide. At least one TRC provides a specific traumatic brain injury neurotrauma outreach program. All FJCs treat victims of all ages and offer Camp HOPE participation to interested children, but some TRCs only treat victims aged 18 and older, and do not have an equivalent camp. ${ }^{5152}$

Without an FJC (or an equivalent model), in many cases, victims need to access multiple locations and struggle with a wide variety of administrative 'red tape' at the same time when their family is in crisis and the risk of harm is significant and immediate. These centers are designed to 'wrap victims in support services and end the frustrating journey for victims of having to go from agency to agency, telling their story over and over again in order to get the help they need'. ${ }^{40}$ This allows for more improved service provision for the abused and their children. For example, a victim who enters an FJC can meet with a victim advocate, file a police report, talk about his/her case with a prosecutor, receive practical assistance (eg, shelter and transportation), and get information on other communitybased support resources all in one location. ${ }^{51}$ Prior to starting an FJC, the following needs to be in order: community readiness, the community leaders should visit another established facility/ model to determine how they function, buy-in from community organizations with a champion to lead the charge, sustainable funding plans, protected information sharing among agencies, and accessibility of the center to all cultural groups. ${ }^{40}$ Concerns and misinformation about immigration were a noted barrier before coming to FJCs in one study, but not afterwards. Survivor 
Table 3 Children's Resiliency (CR) Scores before and after Camp HOPE

\begin{tabular}{lllll}
\hline & $\mathbf{2 0 1 5}(\mathbf{n}=\mathbf{2 2 9})$ & $\mathbf{2 0 1 6}(\mathbf{n}=\mathbf{3 1 4})$ & $\mathbf{2 0 1 7}(\mathbf{n}=\mathbf{7 9 3})$ & $\mathbf{2 0 1 9}(\mathbf{1 1 2 7})$ \\
\hline Pretest CR Score (mean) & 27.53 & 28.41 & 27.75 & 28.29 \\
\hline Post-test CR Score (mean) & 29.96 & 28.69 & 28.21 & 28.74 \\
Follow-up CR Score (mean) & 30.3 & 28.77 & 28.85 & 29.61 \\
\hline
\end{tabular}

concerns included fear of deportation, fear of having children removed, and a lack of awareness of legal services to address immigration and citizenship. One of the most significant benefits of FJC services noted by survivors was receiving immigration services that helped them to become legal residents. ${ }^{49}$

\section{EVIDENCE-BASED EFFECTIVENESS OF CAMP HOPE}

Alliance for HOPE International is an organization that links all FJCs. This organization assists with the establishment of Family Justice/Multi-Agency Centers; provides training on the handling of non-fatal strangulation, holds conferences, provides keynotes, and hosts training around the world. They also help start and operate Camp HOPE America across the USA. ${ }^{6}$ Camp HOPE America is the first and only evidence-based camping and mentoring program in the USA focused solely on children impacted by DV, sexual assault, and child abuse. It began in California and is now creating affiliated Camp HOPE America programs across the USA. ${ }^{6}$ The camp is based on this definition of hope: an individual's motivation to achieve future goals, as well as their belief that they have the ability and means to achieve those goals. An individual's level of hope is related to a host of positive outcomes including education, physical and mental health, and career outcomes. ${ }^{53} 54$

During the past 5 years (2015-2019), several variables were analyzed by researchers at the University of Oklahoma, Tulsa (and then found to be improved) among participants attending Camp HOPE. Adverse Childhood Experiences (ACE) scores of Camp HOPE children (mean: 63\%) were found to be mostly at the level of 4 or greater (range: 1-10), when compared with other children's national level ACE score of 1.61, of similar age groups by the CDC (mean: 12.5\%). With an ACE score of 4 or greater, the likelihood of significant life-altering diseases rises as follows: becoming a victim of DV (300\%), chronic depression (300\%), alcoholism (700\%), attempted suicide (1200\%), and injection heroin abuser (3000\%). The number of participants in Camp HOPE has increased over the years from 234 to 1127 (figure 1), with an age range of 6-18 years. Male:female ratio is 48.3\%:51.7\%. The number of states represented by children who have participated in Camp HOPE increased from 1 to 15 during the study period. Children's Hope Index, range: 6-36 (examines the extent to which children think they can establish and maintain pathways to their goal), Children's Resiliency Score, range: 6-36 (underscores children's belief in themselves, others, and their dreams), and Counselor Observation of Camper Participant Hope Score, range: 6-36 (highlights the observation of

\begin{tabular}{|c|c|}
\hline Year & ANOVA \\
\hline 2015 & $(F(2,162)=14.27 ; p<0.05)$ \\
\hline 2016 & $(F(2,147)=2.23 ; p<0.05)$ \\
\hline 2017 & $(F(2,388)=8.57 ; \mathrm{p}<0.05)$ \\
\hline 2019 & $(F(2,769)=36.34 ; p<0.001)$ \\
\hline
\end{tabular}

ANOVA, analysis of variance. a child gaining confidence in optimism, self-control, gratitude, grit, social intelligence, and curiosity) have remained positive in a constant statistically significant manner $(p<0.05)$. Analysis of variance was done based on the mean difference of pretesting and post-testing. See tables $1-6 .{ }^{622} 2755$

\section{THE CHALLENGE}

Although the concept has significant support, data regarding the effectiveness of FJCs are limited, and a growing number of researchers are beginning to examine the effect of FJCs to address the dearth of data regarding their true impact. Funded research to assess the impact of FJCs is needed. It might be worth noting that the methodological challenges of demonstrating efficacy of FJCs match those experienced by all injury prevention efforts, where process measures (how many attend, services rendered) rather than outcome measures (lives saved) can be tracked. Clients served are typically in a state of crisis, there are multiple privacy and safety concerns and outcomes cross the domains of the criminal justice system, social services and healthcare; however, there is a need for creative, methodologically sound evaluation research to document the impact of FJCs on the clients and communities they serve. Thus far, research has focused on defining FJCs and how to accurately collect data and measure these outcomes. Proximal outcomes primarily focus on individual, client-level impact and include number of clients served, demographic data, type of services received, and impact the services have on clients in areas of satisfaction, safety, empowerment and hope. Longer term outcomes tend to be more challenging, and include lasting systemic changes such as decrease in homicides due to IPV, increase in issuance of restraining orders, and an overall increase in systemic effectiveness in preventing and responding to DV and IPV. A comprehensive data sharing warehouse model with triangulation among FJCs has been suggested. ${ }^{40}$ Partnerships between FJC and trauma centers hold the promise of improved multidisciplinary outcome-related research.

\section{THE MISSING LINK AND THE ROLE OF THE SURGEON}

Teachers, clergy, law enforcement agents, physicians and surgeons often encounter victims of DV, IPV, child abuse, sexual abuse, and elder abuse. They often serve as gatekeepers of these tragic and horrific events and injuries, and are obligated to steer victims in the right direction. Women willing to discuss IPV with their healthcare provider are four times more likely to use an intervention and 2.6 times more likely to leave an abusive relationship. ${ }^{1256}$ A study conducted at an urban, academic level I trauma center demonstrated that $84 \%$ of women patients who sustained injuries secondary to IPV examined in the ED agreed to speak with an in-house patient advocate. One of the most important motivators for seeking help by survivors is the concern for their children. ${ }^{49}$

The role of the surgeon in the care of their patients should not be limited to the boundaries of the operating room or the trauma resuscitation area. Surgeons should recognize the impact we have on every facet of care and should work to address the 
Table 5 Counselor Observation of Camper Participant Hope Scores

\begin{tabular}{lllll}
\hline & $\mathbf{2 0 1 5}(\mathrm{n}=\mathbf{2 2 9})$ & $\mathbf{2 0 1 6}(\mathrm{n}=\mathbf{3 1 4})$ & $\mathbf{2 0 1 7}(\mathrm{n}=\mathbf{7 9 3})$ & $\mathbf{2 0 1 9}(\mathbf{1 1 2 7})$ \\
\hline Pretest CR Score (mean) & 23.23 & 25.03 & 24.82 & 24.53 \\
Post-test CR Score (mean) & 25.13 & 27.69 & 28.05 & 27.55 \\
\hline
\end{tabular}

CR, Children's Resiliency.

root causes of violence. Trauma-Informed Care (TIC) is a rapidly growing concept in the surgical community that raises awareness of inadvertent provider behavior, comments, and attitudes that affect a patient's traumatic event by secondary trauma. Such care plays a critical role in addressing cultural sensitivity, especially in aiding victims of DV/IPV. It behooves trauma centers to adopt the philosophy of the TIC methods of healing and recovery, and not embolden mannerisms that perpetuate such retraumatization. IPV is a serious and underdiagnosed cause of traumatic injury and ED visits. Surgeons must be vigilant in identifying individuals at increased risk for injury secondary to IPV during the COVID-19 pandemic and thereafter, and should be familiar with wrap-around services for survivors of IPV and DV. ${ }^{12}$ In 2014, the American College of Surgeons Committee on Trauma (ACS-COT) recognized the importance of IPV, declaring that 'it is the responsibility of the treating surgeon not only to care for the immediate injury and to reassure the patient, but also to identify resources in his or her hospital and to help identify resources in the community'. ${ }^{1657}$ In addition, The Joint Commission requires hospitals and clinics to screen all patients for IPV and provide ample access to social service support. ${ }^{1658}$

The presence of an FJC in a local area potentially eliminates the multiorganizational transport barrier needed for services, but requires trauma teams to be familiar with these centers. Trauma centers have a role to play in screening and directing unfortunate victims for appropriate services, and are in a position to break the vicious cycle of preventable violence that spans the gamut of all ages and demographic groups. With establishment of an FJC in a county, it provides partnership opportunities between trauma centers and the professionals in the FJC, such that a warm hand-off of victims can be conducted for timely services. In so doing, at-risk victims would reap the benefits of critically important services, which promotes empowerment, and ultimately alight from the potentially dangerous situation in their environment. The ACS-COT verification process mandates that a hospital-based injury prevention program 'must include and track partnerships with other community organizations'. ${ }^{759}$

Creating a partnership negates the retraumatization a victim suffers in seeking compatible support. Raising the awareness factor in the community will hopefully decrease the incidence of 'dual arrests' African-American women suffer. Wide dissemination of the FJC model could also encourage counties without FJCs to potentially begin the process of creating one, and encourage outcomes and efficacy research in those municipalities that already have an FJC. The future of FJCs with

\begin{tabular}{ll}
\hline $\begin{array}{l}\text { Table } 6 \\
\text { Participant Hope Scores }\end{array}$ & $\begin{array}{l}\text { Analysis of variance for Counselor Observation of Camper } \\
\text { Year }\end{array}$ \\
\hline 2015 & ANOVA \\
2016 & $(F(1,219)=30.95 ; p<0.05)$ \\
2017 & $(F(1,296)=47.59 ; p<0.05)$ \\
2019 & $(F(1,546)=151.26 ; p<0.05)$ \\
\hline
\end{tabular}

ANOVA, analysis of variance. recognition and expansion is bright, particularly with local and federal grants to tap into.

\section{CONCLUSION}

A reality of the world we live in is that DV is so pervasive as to require the FJC model on such a large scale. By partnering with FJCs, trauma centers and violence intervention programs can enable more services, promote outcomes research and develop grant funding for sustainment of this not-so-novel, but relatively unknown gem.

Acknowledgements We hereby recognize the extra effort provided by Graal Diaz, $\mathrm{PhD}, \mathrm{MSN}, \mathrm{MA}, \mathrm{CCRNK}$ in producing the figure and tables.

Contributors Concept: TKD. Review of article: TKD, RS, KJ, DAK, TD, ST, SB, and KM. Study concept and design: TKD. Writing the article: TKD, KJ, RS, DAK, TD, ST, SB, KM. All authors read and approved the final article.

Funding The authors have not declared a specific grant for this research from any funding agency in the public, commercial or not-for-profit sectors.

Competing interests None declared.

Patient consent for publication Not required.

Provenance and peer review Not commissioned; externally peer reviewed.

Open access This is an open access article distributed in accordance with the Creative Commons Attribution Non Commercial (CC BY-NC 4.0) license, which permits others to distribute, remix, adapt, build upon this work non-commercially, and license their derivative works on different terms, provided the original work is properly cited, appropriate credit is given, any changes made indicated, and the use is non-commercial. See: http://creativecommons.org/licenses/by-nc/4.0/.

\section{ORCID ID}

Thomas K Duncan http://orcid.org/0000-0003-0357-8046

\section{REFERENCES}

1 Duncan TK, Weaver JL, Zakrison TL, Joseph B, Campbell BT, Christmas AB, Stewart RM, Kuhls DA, Bulger EM. Domestic violence and safe storage of firearms in the COVID-19 era. Ann Surg 2020;272:e55-7.

2 Kuhls DA, Falcone RA, Bonne S, Bulger EM, Campbell BT, Cooper Z, Dicker RA, Duncan TK, Kuncir EJ, Lamis DA, et al. Prevention of firearm injuries: it all begins with a conversation. J Trauma Acute Care Surg 2020;88:e77-81.

3 YouthViolence: AReport of theSurgeonGeneral. Office of the Surgeon General (US); National Center for Injury Prevention and Control (US); National Institute of Mental Health (US); Center forMental Health Services (US). YouthViolence. Rockville (MD): Office of the Surgeon General (US), 2001.

4 Wen LS, Goodwin KE. Violence is a public health issue.J Public Health Manag Pract 2016:22:503-5.

5 Centers for Disease Control and Prevention. Intimate partner violence, 2021.

6 Jackson-Stowe J, Muilenburg-Trevino EM, Hellman CM. A program evaluation of hope and positive youth development. University of Oklahoma, Tulsa: National Results, 2019.

7 Rosenblatt MS, Joseph KT, Dechert T, Duncan TK, Joseph D’Andrea K, Stewart RM, Cooper ZR. American association for the surgery of trauma prevention Committee topical update: impact of community violence exposure, intimate partner violence, hospital-based violence intervention, building community coalitions and injury prevention program evaluation. J Trauma Acute Care Surg 2019;87:456-62.

8 Campbell JC, Webster D, Koziol-McLain J, Block C, Campbell D, Curry MA, Gary F, Glass N, McFarlane J, Sachs C, et al. Risk factors for femicide in abusive relationships: results from a multisite case control study. Am J Public Health 2003;93:1089-97.

9 American College of Obstetricians and Gynecologists. Gun violence and Safety Statement of Public Policy. 2014. https://www.acog.org/Cliniical-Guidance-and./ Statement (31 Jan 2021).

10 American Psychological Association. How COVID-19 may increase domestic violence and child abuse; Ashley Abramson, 2020. 
11 Centers for Disease Control and Prevention,National Center for Injury Prevention and control. The National Intimate Partner and Sexual Violence Survey. 2017. https://www. cdc.gov/violenceprevention/datasources/nisvs/summaryreports.html (31 Jan 2021).

12 Chen AR, Renner LT, Clark THE, Chriver WM. Surgeon's Guide to Intimate Partner Violence in the Era of COVID-19. ACS Bulletin 2020;105:121-5.

13 National Center for Injury Prevention and Control of the Centers for Disease Control and Prevention. The National Intimate Partner and Sexual Violence Survey (NISVS). 2015. www.cdc.gov/violenceprevention/datasources/nisvs/summaryreports.html (31 Jan 2021).

14 Bridges FS, Tatum KM, Kunselman JC. Domestic violence statutes and rates of intimate partner and family homicide. Crim Justice Policy Rev 2008;19:117-30.

15 Dearwater SR, Coben JH, Campbell JC, Nah G, Glass N, McLoughlin E, Bekemeier B. Prevalence of intimate partner abuse in women treated at community hospital emergency departments. JAMA 1998;280:433-8.

16 Oppenheimer-Velez ML, Labiner H, McCoy J, Sas K, Sims CA. Silent no more: intimate partner violence and our surgical colleagues. ACS Bulletin 2020;105:114-20.

17 Black MB, Basille KC, Breiding M. The National Intimate Partner and Sexual Violence Survey: 2010 Summary Report. Centers for Disease Control and Prevention. www.cdc. gov/violenceprevention/pdf/nisvs report2010-a.pdf (31 Jan 2021).

18 Tjaden P, Thoennes N. United States department of justice, National Institute of justice: full report of the prevalence, incidence and consequences of violence against women, 2000

19 Smith SG, Chen J, Basile KC, Gilbert LK, Merrick MT, Patel N. The National intimate partner and sexual violence survey (NISVS):2010-2012 SATE report: National Center for Injury Prevention and Control, Centers for Disease Control and Prevention, editor, 2017.

20 Hayden SR, Barton ED, Hayden M. Domestic violence in the emergency department: how do women prefer to disclose and discuss the issues? J Emerg Med 1997; 15:447-51.

21 National Center for Health Statistics, National Vital Statistics System. 10 leading causes of death, by age group, all and highlighting violence-related deaths, United States. 2017. http://www.cdc.gov/injury/wisqars/LeadingCauses.html (31 Jan 2021).

22 Hellman C, Feeley JA. Camp hope America as an intervention for children exposed to domestic violence: a program evaluation of hope and positive youth development. University of Oklahoma, Tulsa: National Results, 2016.

23 Hamby S, Finkelhor D, Turner H, Ormrod R. Children's exposure to intimate partner violence and other family violence. Office of Juvenile Justice and Delinquency Prevention. OJJDP Bulletin (NCJ232272). Washington, D.C: US Department of Justice, 2011.

24 Evans SE, Davies C, DiLillo D. Exposure to domestic violence: a meta-analysis of child and adolescent outcomes. Aggress Violent Behav 2008;13:131-40.

25 Kitzmann KM, Gaylord NK, Holt AR, Kenny ED. Child witnesses to domestic violence: a meta-analytic review. J Consult Clin Psychol 2003;71:339-52.

26 Wolfe DA, Crooks CV, Lee V, McIntyre-Smith A, Jaffe PG. The effects of children's exposure to domestic violence: a meta-analysis and critique. Clin Child Fam Psychol Rev 2003:6:171-87

27 Hellman CM, Feeley JA. Children Exposed to Domestic Violence: Examining the Effect of Camp HOPE on Children's Hope, Resilience and Strength of Character. University of Oklahoma, Tulsa: National Results, 2015.

28 Fantuzzo JW, Mohr WK. Prevalence and effects of child exposure to domestic violence. Future Child 1999;9:21-32.

29 Carlson BE. Adolescent observers of marital violence. J Fam Violence 1990;5:285-99.

30 Lichter EL, McCloskey LA. The effects of childhood exposure to marital violence on adolescent Gender-Role beliefs and dating violence. Psychol Women Q 2004:28:344-57.

31 Litrownik AJ, Newton R, Hunter WM, English D, Everson MD. Hunter WM. exposure to family violence in young at-risk children: a longitudinal look at the effects of victimization and witnessed physical and psychological aggression. J Fam Violence 2003:18:59-73.

32 Felitti VJ, Anda RF, Nordenberg D, Williamson DF, Spitz AM, Edwards V, Koss MP, Marks JS. Reprint of: relationship of childhood abuse and household dysfunction to many of the leading causes of death in adults: the adverse childhood experiences (ACE) study. Am J Prev Med 2019:56:774-86.

33 Reavis JA, Looman J, Franco KA, Rojas B. Adverse childhood experiences and adult criminality: how long must we live before we possess our own lives? Perm J 2013;17:44-8

34 Alliance for Hope International. 2021. https://www.allianceforhope.com/ (30 Jan 2021)

35 Simmons CA, Howell KH, Duke MR, Beck JG. Enhancing the impact of family justice centers via motivational interviewing. Trauma Violence Abuse 2016;17:532-41.

36 Kern County Family Justice Center. www.kerncounty.com/government/departments/ district-attorney/family-justice-center (31 Jan 2021).

37 Department of Justice. Violence against womens act. SB 557, 2011

38 Family Justice Center. www.familyjusticecenter.org (31 Jan 2021).

39 United States Department of Justice. The President's Family Justice Center Initiative; Best Practices, 2007.

40 E. Murray C, White J, Nemati H, Chow A, Marsh A, Edwards S. A community considers a family justice center: perspectives of stakeholders during the early phases of development. J Aggress Confl Peace Res 2014;6:116-28.

41 Alliance for HOPE International. www.StrangulationTraining Institute.com (31 Jan 2021).

42 Gwinn C, Strack G A. The FJC collaborative model. 2007. http://www. familyjusticecenter.org/ (31 Jan 2021).

43 Townsend M, Hunt D, Rhodes W. Evaluability Assessment of the President's Family Justice Center Initiative Unpublished report. Washington: US Department of Justice, 2005

44 Hoyle C, Palmer N. Family justice centres: a model for Empowerment? Int Rev Vict 2014;20:191-210

45 Johnson MP. Conflict and control: Images of symmetry and asymmetry in domestic violence. In: Booth AC, Clemments M, Couples in conflict. Hillsdale, NJ: Erlbaum, 2000.

46 Bent-Goodley TB. Health disparities and violence against women: why and how cultural and societal influences matter. Trauma Violence Abuse 2007:8:90-104

47 Holland-Davis L, Davis JW. Victim arrest in intimate partner violence incidents: a multilevel test of Black's theory of law. H Publ Prof Sociol 2014;6:1.

48 Hirschel D, Buzawa E, Pattavina A, Faggiani D. Domestic violence and mandatory arrest laws: to what extent do they influence police arrest decisions. J Crim Law Criminol 2007:98:255-98.

49 Petrucci C. Final evaluation results phase // California family justice initiative statewide evaluation: EMT Association. Family Justice Center Alliance, 2013.

50 Cancer Treatment Centers of America. http://www.traumarecoverycenter.org (30 Jan 2021).

51 UCSF. Trauma Recovery Center. http://traumarecoverycenter.org/ (20 Mar 2021).

52 Alliance for Safety and Justice. https://www.traumarecoverycentermodel.org/ (20 Mar 2021).

53 Schubert E. Hope lives here. impact of the family peace center, 2018.

54 Hellman C, Gwinn C, Strack G. Survivor defined success hope and wellbeing. An assessment of the impact of FJC; ACES connection. Family Justice Center. 2017. https://www.familyjusticecenter.org/ (31 Jan 2021).

55 Hellman C, Featherngill J. Camp hope America as an intervention for children exposed to domestic violence. A program evaluation of hope and positive youth development. University of Oklahoma, Tulsa: National Results, 2017

56 McCloskey LA, Lichter E, Williams C, Gerber M, Wittenberg E, Ganz M. Assessing intimate partner violence in health care settings leads to women's receipt of interventions and improved health. Public Health Rep 2006;121:435-44.

57 American College of Surgeons, Committee on Trauma. Statement on intimate partner violence. Bull Am Coll Surg 2014;99:46

58 Scott CJ, Matricciani RM. Joint Commission on accreditation of healthcare organizations standards to improve care for victims of abuse. Md Med J 1994:43:891-8

59 American College of Surgeons, Committee on Trauma. Resources for optimal care of the injured patient. Chicago, II, 2014. 